J. Dairy Sci. 97:5922-5922

http://dx.doi.org/10.3168/jds.2014-97-9-5922

(C) American Dairy Science Association ${ }^{\circledR}, 2014$.

\title{
Erratum to "Effect of an injectable trace mineral supplement containing selenium, copper, zinc, and manganese on immunity, health, and growth of dairy calves" (J. Dairy Sci. 97:4216-4226)
}

A. G. V. Teixeira, F. S. Lima, M. L. S. Bicalho, A. Kussler, S. F. Lima, M. J. Felippe, and R. C. Bicalho

Table 1. Nutrient composition of calf starter diets for farms A and B

\begin{tabular}{lcc}
\hline & \multicolumn{2}{c}{ Starter diet } \\
\cline { 2 - 3 } Composition & Farm A & Farm B \\
\hline DM (\%) & 82.1 & 90.9 \\
CP (\% of DM) & 19.8 & 22.9 \\
NDF (\% of DM) & 29.4 & 31.8 \\
ADF (\% of DM) & 15.7 & 14.1 \\
TDN (\% of DM) & 72 & 77 \\
Ca (\% of DM) & 0.99 & 0.94 \\
P (\% of DM) & 0.64 & 0.78 \\
Mg (\% of DM) & 0.43 & 0.35 \\
K (\% of DM) & 1.40 & 1.01 \\
Na (\% of DM) & 0.35 & 0.39 \\
S (\% of DM) & 1.28 & 0.35 \\
Fe (mg/kg) & 398 & 258 \\
Zn (mg/kg) & 65 & 111 \\
Cu (mg/kg) & 20 & 22 \\
Mn (mg/kg) & $\mathbf{6 6}$ & $\mathbf{1 0 0}$ \\
\hline
\end{tabular}

The last row of Table 1 (page 4217) should show manganese $(\mathrm{Mn})$ content of the diet, not molybdenum (Mo). The corrected table is shown here (corrected data in bold).

The authors regret the error.

\section{REFERENCES}

Teixeira, A. G. V., F. S. Lima, M. L. S. Bicalho, A. Kussler, S. F. Lima, M. J. Felippe, and R. C. Bicalho. 2014. Effect of an injectable trace mineral supplement containing selenium, copper, zinc, and manganese on immunity, health, and growth of dairy calves. J. Dairy Sci. 97(7):4216-4226. 